\title{
FENOLOGIA E PRODUÇÃO DA VIDEIRA 'NIAGARA ROSADA' CONDUZIDA EM MANJEDOURA NA FORMA DE Y SOB TELADO PLÁSTICO DURANTE AS SAFRAS DE INVERNO E DE VERÃO ${ }^{1}$
}

\author{
JOSÉ LUIZ HERNANDES², MÁRIO JOSÉ PEDRO JÚNIOR ${ }^{3}$, GABRIEL CONSTANTINO BLAIN ${ }^{4}$
}

RESUMO - Realizou-se experimento em vinhedo comercial de 'Niagara Rosada' conduzido em Y sob telado plástico, na região produtora de Louveira (SP), objetivando avaliar as variáveis fitotécnicas (produção, massa e tamanho dos cachos) e fenológicas, durante as safras de verão e de inverno. A produção, a massa dos cachos, o comprimento e a largura dos cachos mostraram uma tendência de serem superiores na safra de verão em relação à de inverno. Os valores de produtividade estimada variaram entre 30 e 35 t.ha $^{-1}$ durante as safras de verão e entre 20 a 22 t.ha-1 para as de inverno. A duração de ciclo na safra de inverno (125 dias) foi menor em comparação com a de verão (140 dias).

Termos para indexação: uva de mesa, sistema de condução, manjedoura, Vitis $s p$.

\section{YIELD AND PHENOLOGY OF THE 'NIAGARA ROSADA' TABLE GRAPE TRAINED ON A Y SHAPED TRELLIS UNDER PLASTIC SCREEN OVERHEAD COVER}

\begin{abstract}
A field trial was carried out in a 'Niagara Rosada' table grape vineyard trained on a Y shaped trellis system under permeable plastic overhead cover at Louveira (São Paulo State, Brazil) from 2008 to 2011 aiming to evaluate yield, bunch characteristics and phenology for the summer and winter growing seasons. Yield, cluster weight and size showed higher values during the summer growing season when compared to the winter season. The mean values of yield ranged from 30 to $35 \mathrm{t}^{-h a^{-1}}$ for the summer growing season and from 20 to 22 t.ha $^{-1}$ for the winter season. Also the cycle length during the winter (125 days) was shorter when compared to the summer (140 days) growing season.
\end{abstract}

Index terms: table grape, training system, Vitis $s p$.

\section{INTRODUÇÃO}

A região compreendida pelos municípios de Jundiaí e Louveira é uma das principais produtoras de uvas para mesa. Nessas localidades, o viticultor utiliza normalmente a cultivar Niagara Rosada conduzida em espaldeira.

Recentemente foi introduzido na região o sistema de condução em manjedoura, na forma de Y (ALARCON et al., 2010; PEDRO ÚNIOR et al., 2011), como preconizado em Santa Catarina. Esse sistema de condução, apesar do custo inicial de implantação mais elevado, tem sido utilizado para uvas de vinho em Santa Catarina e no Rio Grande do Sul (CHAVARRIA et al., 2009; CARDOSO et al., 2008: MOTA et al., 2008) por permitir a produção de uvas de melhor qualidade (SCHUCK et al., 2004).
Dentre os problemas enfrentados pelo viticultor paulista no processo produtivo, destacam-se as constantes perdas pela ocorrência de granizo. $\mathrm{O}$ sistema de condução em Y facilita a utilização do cultivo protegido com cobertura plástica ou de telado (SCHUCK et al., 2004; EPAGRI, 2005), que protegem as videiras contra a ação danosa do granizo. Além disso, visando a aumentar a renda, o viticultor tem produzido duas safras por ano. Uma durante o período normalmente utilizado na região, durante o verão, com poda em julho/agosto e colheita em dezembro/janeiro, e outra, extemporânea, durante o período de outono e inverno, com poda efetuada em janeiro/fevereiro e colheita em abril/maio.

A poda extemporânea, já relatada por Souza (1959) e utilizada na região de Jundiaí desde a década de 1980 (MARTINS et al., 2010), foi atualmente im-

\footnotetext{
${ }^{1}$ Trabalho Sinfruit 086 - Simpósio Internacional de Fruticultura - Avanços na Fruticultura (17 a 21 Outubro)

${ }^{2}$ Biólogo MS., PqC Centro de Fruticultura, IAC, Jundiaí-SP, Brasil. E-mail: jlhernandes@iac.sp.gov.br

${ }^{3}$ Eng. Agr. Dr., PqC Centro de Ecofisiologia e Biofísica, IAC, Campinas-SP, Brasil. E-mail: mpedro@iac.sp.gov.br Bolsista do CNPQ

${ }^{4}$ Eng. Agrícola Dr., PqC Centro de Ecofisiologia e Biofísica, IAC, Campinas-SP, Brasil. E-mail: gabriel@iac.sp.gov.br.
} 
plantada em vinhedos situados na região cafeeira do sul de Minas Gerais (MOTA et al., 2006). Utilizando a técnica de poda extemporânea em uva para vinho, Amorin et al. (2005) e Favero et al. (2008) verificaram a viabilidade de produção da videira 'Syrah' em ciclo de outono inverno, em Minas Gerais, relatando ser possível a alteração do ciclo normal da videira. No caso da videira 'Niagara Rosada', a produção em época extemporânea foi avaliada por Abrahão et al. (2002) na região sul de Minas Gerais. Na segunda safra, obtiveram cachos de bagas de menor tamanho, porém de excelente qualidade e, principalmente, durante a entressafra, a obtenção de maior valor de venda do produto. Roberto et al. (2002), no norte do Paraná, avaliaram a poda extemporânea, tendo em vista melhorar a produção fora de época. Também Souza e Fochesato (2007), em Eldorado do Sul (RS), obtiveram duas safras por ciclo vegetativo da 'Niagara Branca', possibilitando, com podas em novembro e colheita em março e abril, uma alternativa de ampliação do período de oferta do produto no mercado. Ainda, Anzanello et al. (2008), na região da depressão Central do Rio Grande do Sul, com manejo adequado da poda, alteraram a fenologia da videira 'Niagara Branca', obtendo colheitas em março e abril, conseguiram obter mais de uma safra por ano. Mais tarde, Anzanello et al. (2010) mostraram a viabilidade de obtenção, por meio do uso da poda seca e da poda verde, de duas safras por ciclo vegetativo para as videiras 'Niagara Branca' e 'Niagara Rosada'.

Portanto, levando em consideração as vantagens da utilização conjunta das técnicas de cultivo da videira 'Niagara Rosada' no sistema de condução em manjedoura, sob telado plástico e a possibilidade de duas safras por ano, foi realizado um experimento na região de Louveira (SP), objetivando detectar possíveis diferenças entre as safras de verão e de inverno, considerando-se as variáveis: duração do ciclo, produção, massa e tamanho dos cachos.

\section{MATERIAL E MÉTODOS}

O experimento foi realizado em vinhedo comercial de 'Niagara Rosada', situado no município de Louveira (SP). De acordo com a classificação de Köeppen, o clima da região é Cfa, definido como subtropical (mesotérmico). O ensaio foi conduzido durante as safras de inverno e verão de 2008 , verão de 2009 e 2010, e inverno de 2011, em videiras "Niagara Rosada' enxertadas sobre o porta-enxertos IAC 766 e conduzidas em manjedoura, na forma de "Y" (EPAGRI, 2006), com cobertura de telado plástico (clarite com 18\% de transmissão de radiação solar cobrindo as ruas). O espaçamento do vinhedo foi de
2,8 $\mathrm{m}$ entre ruas e 1,6 $\mathrm{m}$ entre plantas. Foram feitos os seguintes tipos de poda: de verão (extemporânea) e de inverno (normal). As podas de verão (poda mixta) foram realizadas em: 5-01-2008 e 25-01-2011, enquanto as podas de inverno foram feitas em: 2008-2008; 19-08-2009 e 10-08-2010.

As avaliações realizadas nas videiras, em 30 plantas, na época da colheita, constaram de: produção $\left(\mathrm{kg}\right.$.planta $\left.{ }^{-1}\right)$; número de cachos por planta, massa dos cachos (g); comprimento e largura dos cachos $(\mathrm{cm})$. Os valores de massa dos cachos e de produção foram medidos com balança de precisão de $1 \mathrm{~g}$, enquanto a largura e o comprimento dos cachos foram determinados com régua graduada em milímetros. A produtividade foi estimada em função da produção por planta e pelo número de plantas por hectare. Inicialmente, as amostras coletadas em cada safra foram submetidas ao teste de lilliefors, conforme descrito em Wilks (2006), a fim de verificar se as mesmas podem ser consideradas oriundas de populações com distribuição normal. Após essa etapa, empregou-se a análise ANOVA para verificar a existência de diferenças estatísticas entre as médias obtidas ao longo das diferentes safras de cada variável analisada. Tanto para o teste de Tukey quanto para o intervalo de confiança, que foram utilizados na análise das diferenças entre cada safra, o nível de significância adotado foi de $5 \%$.

\section{RESULTADOS E DISCUSSÃO}

Os valores médios obtidos durante as safras de verão e de inverno, para a 'Niagara Rosada' conduzida em Y sob telado plástico, de duração dos diferentes subperíodos fenológicos e de parâmetros fitotécnicos (massa, comprimento e largura dos cachos; número de cachos e produção) estão apresentados nas Tabelas 1 e 2, enquanto sua comparação, utilizando intervalo de confiança, está apresentada na Figura 1.

Fenologia - Na Tabela 1, são apresentados os valores médios da duração dos subperíodos: poda-florescimento; florescimento-início da colheita; início-final da colheita e poda-final da colheita. Pode-se verificar que o subperíodo poda-florescimento variou de 33 a 36 dias, não apresentando diferenças importantes entre as safras analisadas. Esses valores são semelhantes aos obtidos por Pedro Júnior et al. (1994) para 'Niagara Rosada' conduzida em espaldeira, em Jundiaí (SP). A duração do subperíodo: florescimento-início da colheita variou entre 79 e 94 dias. Durante as safras de verão, em média, a duração do subperíodo foi de 92 dias, enquanto na safra de inverno foi de 80 dias, sendo esta a maior diferença, 
do ponto de vista fenológico, entre as safras de verão e de inverno. Do início ao final da colheita, verificou-se que a duração do subperíodo variou entre $10 \mathrm{e}$ 14 dias. A duração deste subperíodo é influenciada pela pressão do consumidor, que induz o viticultor a colher seu produto rapidamente para colocação no mercado.

A duração do ciclo total (poda-colheita) variou entre 124 e 141 dias em função das condições climáticas e da safra considerada. Observou-se que, para safra de verão, a duração do ciclo variou entre 138 e 140 dias, enquanto a de inverno durou 125 dias. Essa menor duração do ciclo foi também relatada por Scarpare (2007) para a 'Niagara Rosada' conduzida em espaldeira, na região de Piracicaba (SP). O autor obteve durações de 128 e 138 dias, perspectivamente, para as safras de inverno e de verão. Pode ser notado pela Tabela 1 que a diferença da duração do ciclo durante as safras de verão e de inverno foi influenciada, principalmente, pelo subperíodo florescimento-início da colheita, que foi mais longo em cerca de 10 dias na safra de verão, em relação à de inverno.

Produção e número de cachos - Na Tabela 2 , estão apresentados os valores médios da produção por planta, produtividade estimada e número de cachos. Foi verificado que as produções das safras do verão de 2008 e 2009 foram superiores e estatisticamente diferentes das safras do inverno de 2008 e de 2011. Os valores médios para as safras de verão variaram entre 13,4 e 15,7 kg.planta ${ }^{-1}$. Deve-se ressaltar que, para safra de verão de 2010 , obteve-se uma produção de $9,15 \mathrm{~kg}$ planta $^{-1}$, valor inferior às produções das safras de 2008 e de 2009. Essa menor produção no ano de 2011, provavelmente, seja devida à ocorrência, durante as fases do florescimento, pós-florescimento e chumbinho, de sequência de vários dias com temperatura mínima inferior a $10^{\circ} \mathrm{C}$, aliado a um período sem chuvas de cerca de 30 dias, conforme dados meteorológicos do IAC-APTA-SAA, que pode ter influenciado no pegamento das flores, reduzindo o número de bagas e, consequentemente, diminuindo a massa dos cachos (252g) (Tabela 2). Além disso, durante a safra de verão de 2010, observou-se menor número de cachos por planta $(36,3)$, sendo inferior às outras safras, levando à menor produção das videiras.

Durante as safras de inverno, obtiveram-se produções médias entre 9,03 e 9,89 kg.planta ${ }^{-1}$, tendo sido esses valores estatisticamente inferiores às safras de verão, excetuando-se a de 2010.

A produtividade estimada variou entre $30 \mathrm{e}$
35 t.ha $^{-1}$ e 20 a 22 t.ha ${ }^{-1}$, respectivamente, para as safras de verão, exceto a de 2010 e de inverno. Esses valores obtidos na safra de verão são semelhantes aos relatados por Pedro Júnior et al. (2011), em vinhedos de 'Niagara Rosada' conduzidos em Y e superiores à produtividade, na região, dos vinhedos conduzidos em espaldeira (PEDRO JÚNIOR et al., 2006; ORLANDO et al., 2003).

Apesar de a safra de inverno ser uma opção econômica de aumento de renda do viticultor, a produtividade é menor em comparação com a de verão. Ainda, em função de verificar menor vigor das videiras, muitas vezes, o produtor opta por não fazer poda de verão, como ocorrido nas safras de 2009 e 2010, permitindo intervalos de pousio, procurando evitar o esgotamento e a redução drástica da vida útil dos vinhedos.

O número de cachos por planta, apesar das diferenças estatísticas dos valores obtidos para as diferentes safras, mostrou uma tendência de serem superiores no verão ( 43 a 53 cachos por planta) em relação à safra de inverno de 2008 (34 cachos). As exceções foram a safra de verão de 2010 (36 cachos) pelos motivos expostos na avaliação da produção e a de inverno de 2011 (44 cachos), que pode ter sido uma resposta da videira à baixa produção de 2010 , permitindo maior acúmulo de reservas, expressando maior vigor no ano seguinte. Na região, ocorre naturalmente alternância na produção da 'Niagara Rosada'.

Características do cacho - Os valores de massa dos cachos variaram nas safras de verão de 2008 e 2009 entre 296 e 310 g, diferindo estatisticamente das safras de inverno de 2008 e 2011, cujos valores médios foram entre 224 e 265 g. Exceção deve ser feita à safra de verão de 2010 , cujo valor médio obtido de massa dos cachos ( $252 \mathrm{~g}$ ) não diferiu estatisticamente dos valores da safra de inverno.

Os valores obtidos de massa dos cachos, neste experimento, foram superiores aos obtidos por Pedro Júnior et al. (2011) e Orlando et al. (2003). Também, excetuando-se a safra de verão de 2010, os valores de comprimento e largura dos cachos mostraram uma tendência de serem superiores nas safras de verão em relação às de inverno.

Na Figura 1, são apresentados os valores médios das variáveis fitotécnicas avaliadas e do intervalo de confiança ( $5 \%$ de probabilidade) para melhor visualização das diferenças ocorridas entre as safras de verão e de inverno para a 'Niagara Rosada' conduzida em Y sob telado plástico. 
TABELA 1 - Duração de diferentes subperíodos fenológicos da videira 'Niagara Rosada' conduzida em Y sob telado plástico para as safras de inverno e de verão, em Louveira (SP).

Subperíodo fenológico

\begin{tabular}{lcccc}
\cline { 2 - 5 } \multicolumn{1}{c}{ Safra } & $\begin{array}{c}\text { Poda - } \\
\text { Florescimento }\end{array}$ & $\begin{array}{c}\text { Florescimento - } \\
\text { Início da colheita }\end{array}$ & $\begin{array}{c}\text { Início da colheita - } \\
\text { Final da colheita }\end{array}$ & $\begin{array}{c}\text { Poda - } \\
\text { Colheita }\end{array}$ \\
\hline Inverno - 2008 & 34 & 80 & 10 & 124 \\
Verão - 2008 & 36 & 89 & 13 & 138 \\
Verão - 2009 & 33 & 94 & 14 & 141 \\
Verão - 2010 & 36 & 94 & 10 & 140 \\
Inverno - 2011 & 34 & 79 & 12 & 125 \\
\hline
\end{tabular}

TABELA 2. Valores médios de produção, massa dos cachos, número de cachos, comprimento e largura dos cachos e das bagas em vinhedo de 'Niagara Rosada' conduzido em Y sob telado plástico, em Louveira (SP), para safras de verão e de inverno.

\begin{tabular}{lccccc}
\hline & \multicolumn{5}{c}{ Safra } \\
\cline { 2 - 6 } Variável & Inverno & Verão & Verão & Verão & Inverno \\
& 2008 & 2008 & 2009 & 2010 & 2011 \\
Produção (kg.planta $\left.{ }^{-1}\right)$ & $9,03 \mathrm{c}$ & $13,39 \mathrm{~b}$ & $15,70 \mathrm{a}$ & $9,15 \mathrm{c}$ & $9,89 \mathrm{c}$ \\
Produtividade $\left(\mathrm{t} . h a^{-1}\right)$ & 20,16 & 29,89 & 35,04 & 20,42 & 22,08 \\
Massa do cacho (g) & $265,0 \mathrm{~b}, \mathrm{c}$ & $309,8 \mathrm{a}$ & $295,5 \mathrm{a}$ & $252,0 \mathrm{~b}, \mathrm{c}$ & $223,8 \mathrm{c}$ \\
Comprimento do cacho $(\mathrm{cm})$ & $13,9 \mathrm{a}, \mathrm{b}$ & $14,7 \mathrm{a}$ & $14,2 \mathrm{a}$ & $12,8 \mathrm{c}$ & $13,3 \mathrm{~b}, \mathrm{c}$ \\
Largura do cacho $(\mathrm{cm})$ & $7,9 \mathrm{c}$ & $9,9 \mathrm{a}$ & $8,7 \mathrm{~b}$ & $7,0 \mathrm{~d}$ & $6,3 \mathrm{e}$ \\
Número de cachos & $34,1 \mathrm{c}$ & $43,2 \mathrm{~b}$ & $53,1 \mathrm{a}$ & $36,3 \mathrm{c}$ & $44,2 \mathrm{~b}$ \\
\hline
\end{tabular}

Médias seguidas de mesma letra na horizontal não diferem entre si, pelo teste t a 5\%
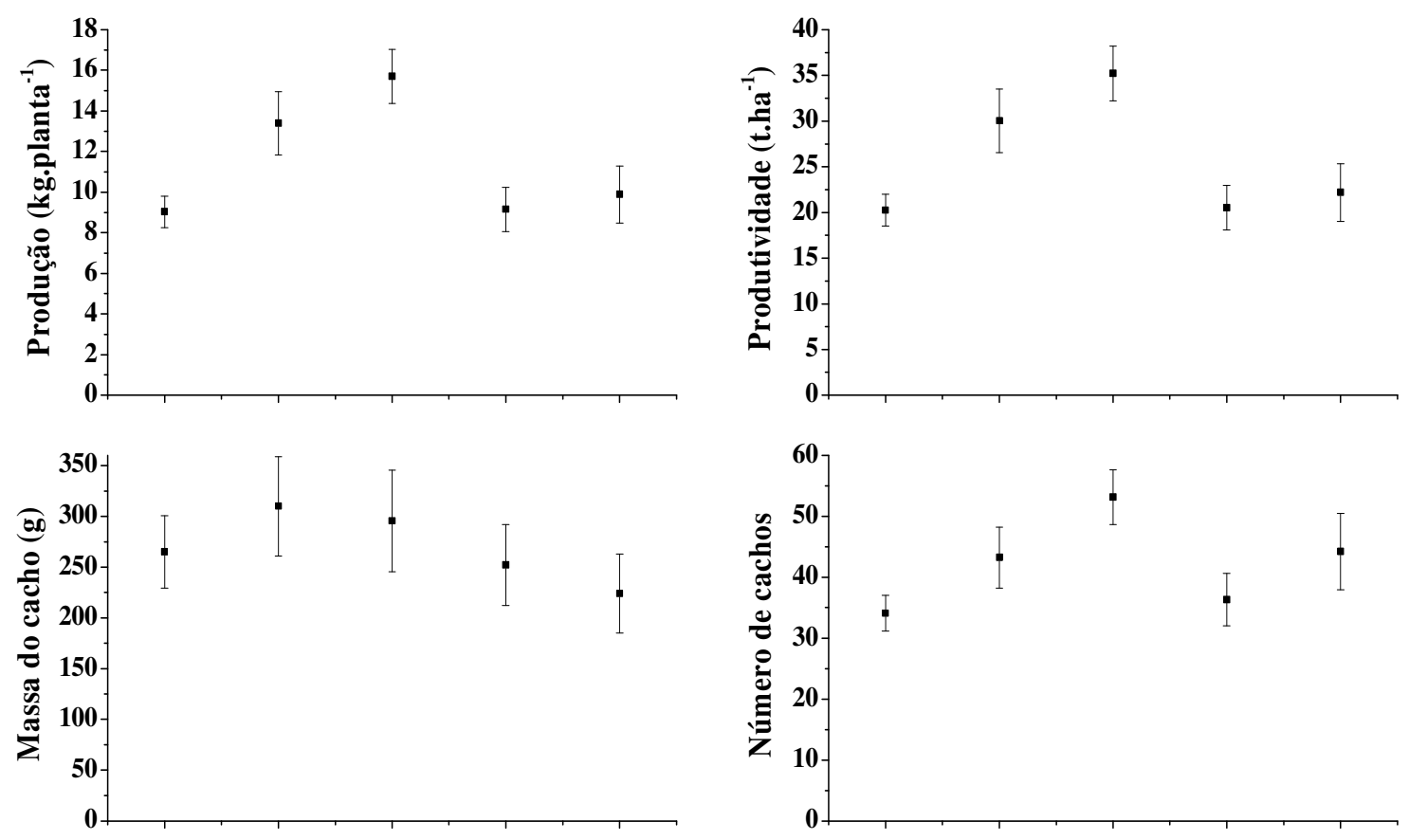

continua... 

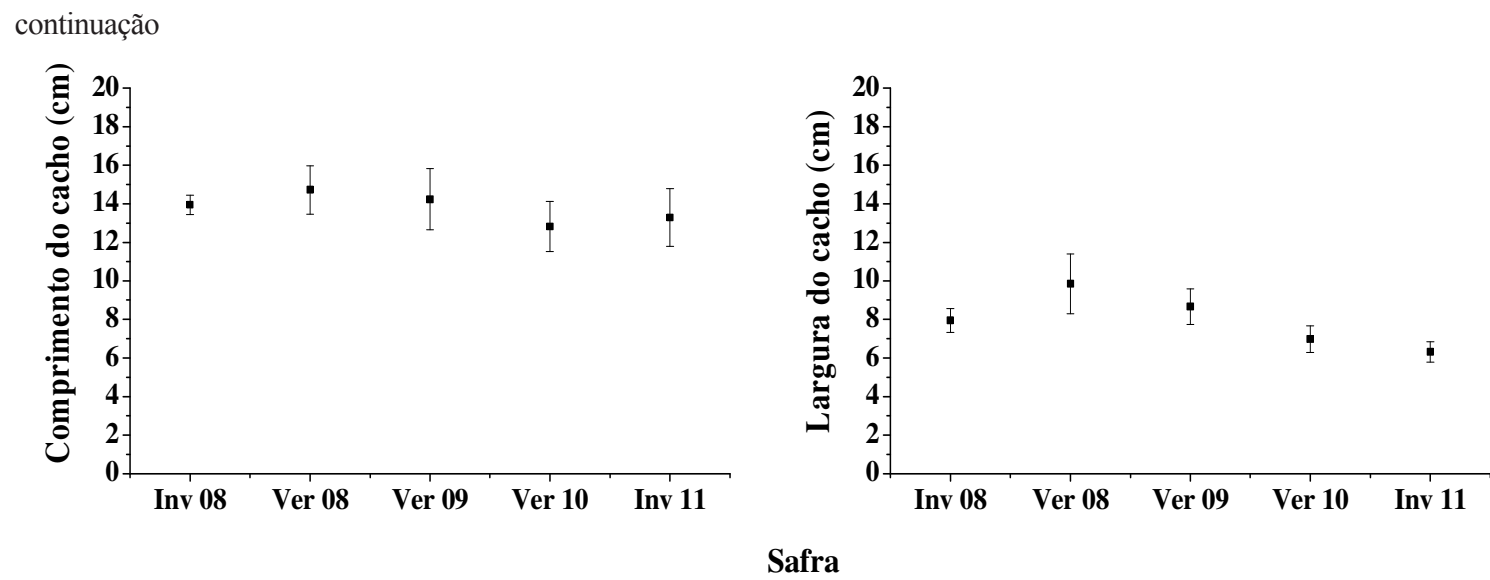

FIGURA 1. Médias de variáveis fitotécnicas e intervalo de confiança para 'Niagara Rosada' conduzida em Y sob telado plástico, durante as safras de inverno e de verão.

\section{CONCLUSÕES}

Os valores das variáveis fitotécnicas e fenológicas obtidos em vinhedo de 'Niagara Rosada' conduzida em Y sob telado plástico mostram que, apesar de a safra de inverno ser uma opção economicamente interessante ao viticultor, tanto a produção quanto a massa dos cachos tendem a ser menores em comparação com a safra de verão. Verificou-se, ainda, que a duração do ciclo (poda-colheita) é menor nas safras de inverno quando comparada à de verão, em função da redução do subperíodo florescimento-início da colheita.

\section{REFERÊNCIAS}

ABRAHÃO, E.; ALVARENGA, A.A.; FRÁGUAS, J.C.; REGINA, M.A.; SILVA, V.J. Potencialidades do município de Lavras-MG, para produção extemporânea de uvas 'Niagara Rosada' para mesa. Ciência e Agrotecnologia, Lavras, v.26, n.4, p.865-868, 2002.

ALARCON, L.C.M.; MICHELLETO, D.; PORTAS, A.A.; BUENO, S.C.S. Implantação do vinhedo. In: BUENO, S.C.C. (Ed.). Vinhedo paulista. Campinas: CATI, 2010. p.55-86.

AMORIN, D.A.; FAVERO, A.C.; REGINA, M.A. Produção extemporânea da videira cultivar Syrah, nas condições do sul de Minas Gerais. Revista Brasileira de Fruticultura, Jaboticabal, v. 27, n.2, p.327-331, 2005.
ANZANELLO, R.; SOUZA, P.V.D.; COELHO, P.F. Uso de poda seca e da poda verde para obtenção de duas safras por ciclo vegetativo em três cultivares de videira. Revista Brasileira de Fruticultura, Jaboticabal, v.32, n.1, p.196-203, 2010.

ANZANELLO, R.; SOUZA, P.V.D.; GONZATTO, M.P. Produção de videiras 'Niagara Branca' e 'Concord' submetidas a duas safras por ciclo vegetativo na Depressão Central do Rio Grande do Sul. Scientia Agraria, Piracicaba, v.9, n.3, p.311-316, 2008.

CARDOSO, L.S.; BERGAMASCHI, H.; COMIRAN, F.; CHAVARRIA, G.; MARODIN, G.A.B.; DALMAGO, G.A.; SANTOS, H.P; MANDELLI, F. Alterações micrometeorológicas em vinhedos pelo uso de coberturas de plástico. Pesquisa Agropecuária Brasileira, Brasília, v.43, p.441447, 2008.

CHAVARRIA, G.; CARDOSO, L.S.; BERGAMASCHI, H.; SANTOS, H.P.; MANDELLI, F.; MARODIN, G.A.B. Microclima de vinhedos sob cultivo protegido. Ciência Rural, Santa Maria, v.39, p.2029-2034, 2009.

EPAGRI. Normas técnicas para o cultivo da videira em Santa Catarina. Florianópolis: Epagri, 2005. 67 p. (Sistemas de Produção, 33). 
FAVERO, A.C.; AMORIM, D.A.; MOTA, R.V.; SOARES, A.M.; REGINA, M.A. Viabilidade de produção da videira 'Syrah', em ciclo de outono-inverno, na região de Minas Gerais. Revista Brasileira de Fruticultura, Jaboticabal, v. 30, n.3, p.685-690, 2008.

MARTINS, F. P.; PIRES, E. J. P.; HERNANDES, J. L.; TERRA, M. M.; MOURA, M. F.; CIA, P. Uva. In: DONADIO, L. C. (Org.). História da fruticultura paulista. Jaboticabal: Sociedade Brasileira de Fruticultura, 2010. p. 303-368.

MOTA, C.S.; AMARANTE, C.V.T.; SANTOS, H.P.; ZANARDI, O.Z. Comportamento vegetativo e produtivo de videiras 'Cabernet Sauvignon' cultivadas sob cobertura plástica. Revista Brasileira de Fruticultura, Jaboticabal, v. 30, n.1, p.148-153, 2008.

MOTA, R.V.; REGINA, M.A.; AMORIN, D.A.; FÁVERO, A.C. Fatores que afetam a maturação e a qualidade da uva para vinificação. Informe Agropecuário, Belo Horizonte, v.27, n.234, p.5664, 2006.

ORLANDO, T.G.S.; REGINA, M.A.; SOARES, A.M.; CHALFUN, N.N.J.; SOUZA, C.M.; FREITAS, G.F.; TOYOTA, M. Caracterização agronômica de cultivares de videira 'Niagara Rosada' (Vitis labrusca L.). Ciência e Agrotecnologia, Lavras, v.27, p.1460-1469, 2003. Edição especial.

PEDRO JÚNIOR, M. J.; HERNANDES, J. L.; ROLIM, G. S. Sistema de condução em Y com e sem cobertura plástica: efeitos no microclima, produção, qualidade do cacho e ocorrência de doenças fúngicas na videira 'Niagara Rosada'. Bragantia, Campinas, v. 70, p. 28-233, 2011.

PEDRO JÚNIOR, M.J.; SENTELHAS, P.C.; POMMER, C.V.; MARTINS, F.P. Determinação da temperatura-base, graus-dia e índice biometerológico para a videira 'Niagara Rosada'. Revista Brasileira de Agrometeorologia, Santa Maria, v.2, p.51-56, 1994.
PEDRO JÚNIOR, M.J.; PEZZOPANE, J.R.M.; HERNANDES, J.L.; ABRAMIDES, P.L.G. Sistemas de condução da videira 'Niagara Rosada': efeitos na transmissão de radiação solar e na produtividade. Revista Brasileira de Agrometeorologia, Piracicaba, v.14, n.1, p.1-9, 2006.

ROBERTO, S.R.; KANAI, H.T.; YANO, M.Y.; SASANO, E.M.; GENTA, W. Avaliação da brotação e da fertilidade de gamas da videira 'Niagara Rosada' submetida a diferentes intensidades de poda de frutificação. Semina: Ciências Agrárias, Londrina, v.23, n.2, p.185-190, 2002.

SCARPARE, F.V. Determinação de índices biometeorológicos da videira 'Niagara Rosada' (Vitis labrusca L.) podada em diferentes épocas e fases do ciclo vegetativo. 2007. 76 f. Dissertação (Mestrado) - Escola Superior de Agricultura Luiz de Queiroz - Universidade de São Paulo, Piracicaba, 2007.

SCHUCK, E.; CALIARI, V.; ROSIER, J.P. Uso da plasticultura na melhoria da qualidade de frutas. In: ENFRUTE, 7., 2004. Friburgo. Anais... 8p.

SOUSA, J.S.I. Origens do vinhedo paulista. Jundiaí: Editora Obelisco, 1959. 319p.

SOUZA, P.V.D.; FOCHESATO, M.L. Emprego da poda verde para obtenção de duas safras por ciclo vegetativo em 'Niagara Branca'. Bragantia, Campinas, v.66, n.4, p.611-616, 2007.

WILKS, D.S. Statistical methods in the atmospheric sciences. $2^{\text {nd }}$ ed. San Diego: Academic Press, 2006. 629p. 